\title{
Development Prospects of Industrial Economics Based on Mobile Information Systems
}

\author{
Zhen Wang $\mathbb{1}$ \\ Zhongzhi Enterprise Service (Shandong) Technology Service Co. Ltd., Jinan 250102, Shandong, China \\ Correspondence should be addressed to Zhen Wang; 20200120695@nxmu.edu.cn
}

Received 11 September 2021; Revised 29 December 2021; Accepted 27 January 2022; Published 1 March 2022

Academic Editor: Sang-Bing Tsai

Copyright ( 2022 Zhen Wang. This is an open access article distributed under the Creative Commons Attribution License, which permits unrestricted use, distribution, and reproduction in any medium, provided the original work is properly cited.

\begin{abstract}
In this era of developed network communication, this paper analyzes the development prospect of industrial economy based on mobile information systems. Firstly, this paper compares and analyzes the relationship between the information industry and industrial economics, constructs the framework diagram between them, then establishes the VAR model to simulate the industrial economy, statistically compares the industrial economies from 2005 to 2016, and finally uses the impulse response function to correct and calculate the data results. This paper deeply analyzes the industrial economy based on mobile information, compares enterprises and small assets, studies the evolution and development law of traditional industries based on mobile information, summarizes the impact of "modular" manufacturing on the production organization of information companies, and reveals the "virtual vertical integration" of information industry manufacturing enterprises. The data show that most of the industrial economy in the first 10 years has a downward trend, with a small increase, but it is not obvious. Finally, it is concluded that the industrial economy will show a downward trend in recent years, and the annual downward trend is about $5 \%$.
\end{abstract}

\section{Introduction}

With the rapid development of science and technology, information transmission technology continues to improve. The needs of users for a variety of services are increasing day by day. Traditional communication tools such as televisions, computers, and telephones used to transmit information have gradually narrowed the boundaries. Nowadays, a smart phone can fulfill people's requirements for communication, surfing the Internet, or watching TV programs. The three previously independently operated networks, the telecommunications network, the Internet, and the cable television network, are continuously merging with each other through various methods and channels. At the same time, the technology and business aspects of the three major information industries also penetrate and merge with each other. In this era of information flooding and knowledge based on academic qualifications, the current knowledge industry is far more than the traditional industry in the past, and enterprises are no longer limited to local resource customers, but have the opportunity to become global customers. Challenges coexist, and the company's competitors have expanded from local to global.

Industrial economics is a subject that is difficult to understand and covers a wider range of subjects than Penguins. It links some economic development laws with some economic activities, so as to start a specific industrial economic analysis, starting from the "industry," and revealing the development of the industry. The interaction between industry organizations and the links between industry and economic activities and laws unique to other industries; these economic activities and behaviors are in step, and their relationships are closely intertwined. In this way, the intermediate level of the economy and the national economy has formed its own development laws and characteristics. The main research projects of industrial economics include the development of industries in various regions or industries and the relationship between a single industry and other industries, the 
economic impact of a certain industry on surrounding areas or surrounding industries, and the qualitative and quantitative relationships between industries. The industrial model studies the impact of a country or region's industrial layout on the entire economy from the influence of its surroundings. Most of the research methods of industrial economics use systematic analysis methods, based on statistics, and then conduct a logical analysis to study the impact of other factors on the industrial economy.

According to the mobile data era, different researchers have analyzed the industrial economy in different ways. In terms of the particularity and dynamics of the media industry, Myaskov and Alekseev applied strict scientific and industrial classification principles based on the development of science and technology, studied and summarized the laws of the media industry, refined, merged, evolved, and implemented the industrial economic classification system $(f, D)$. The relativity criterion corrects the shortcomings of classification. The "one" of some industries provides a strict interpretation of the traditional industry classification and mathematical meaning. However, this theory has some flaws and is not perfect [1]. Ferguson and Sanctuary took the system dynamics model as the central element and combined the input-output method, multiplication method and econometric model to analyze the economic impact of Lingang Industrial Zone and used VENSIM software to simulate the system dynamics of the economic impact of Lingang Industrial Zone. Basic simulation and policy simulation will analyze the impact of policies on development, but this research is limited and inconsistent [2]. Kim conducted a theoretical analysis of the relationship between tourism and regional economic development and then used system dynamics theory to model the interactive relationship between tourism and regional economic development, focusing on the relationship between tourism and economic development in university communities for a long time a new research concept has been formed. But this new concept is not mature enough to be used [3]. Kim and Song described the system economy of cooperative competition and used it as a forum to discuss the necessity and feasibility of cooperative competition in the radio and television industry. The theme and background are the types and forms of industry cooperative competition. In addition, with the cooperation of the radio and television industry and the experience of international competition, the idea of developing cooperation and competition in the radio and television industry in my country has emerged, but the research methods are insufficient and outdated [4]. Ferreira analyzed and studied the integration relationship between the industrial ecosystem and the industrial economy on this basis, presented the connotation and importance of industrial ecology, and proposed a sustainable industrial ecosystem and industrial economic development model in the future, and provided new ideas to enable the future economy benefit and ecological balance develop together. But this research did not fully address the problems based on complex network theory [5]. Bongchan analyzed the complexity of circular economy industrial chain structure, established a complex circular economy industrial chain network evaluation model and industrial chain, and empirically studied two different circular economy systems: Gujiao Circular Economy Park of coal power group and Tashan Circular Economy Park of Tongmei group, but the research method is too strict and inflexible [6]. Eungsoon and Yong combines relevant advanced research results and research theories. An important theory in macroeconomics is economic growth accounting theory. It then provides enlightenment and content on the content of industrial economic development within the framework of macroeconomics, and then from industry optimization, industrial foundation, and political leadership aspects, discusses the industrial economic development policy from the perspective of macroeconomics, but the research is not enough to discuss this issue [7].

Search the core journals and journals with relatively high impact factors in CNKI through keywords such as "big data industry", "listed company", and "regional economy", summarize the relevance of these three, and consult the big data industry. On the basis of literature analysis, a theoretical model is derived and a more reasonable research hypothesis is put forward. Using Stata13.1 analysis software, from the perspective of the scale of big data listed companies and economic activities, the number of companies, financing activities, and investment activities are selected as independent variables, and the city's GDP is used as the dependent variable, and an unbalanced panel is constructed for empirical analysis. Start from the economic significance of the indicators affecting the economic development of the "East, Middle, and West" parts of the country and subregions, combined with the regression coefficients of the equation to demonstrate the role of different economic activities of the regional big data listed companies in the regional economic growth.

\section{The Definition and Introduction of the Economic Theory of the Mobile Information Industry}

2.1. Information Industry. Industry is also a concept put forward in the early twenty-first century, but this is not a general term for all walks of life. It is a concept used to measure whether the economic system of a society or even a country is strong. In the society, due to the division of labor, the traditional industry is separated from the modern industry, forming a contemporary industrial economic system [8].

If there is no division of labor, there will be no industry, and the essence of industry is the phenomenon of social division of labor. The process of social division of labor and industrial development is the process of improving social productivity. On the one hand, the formation and development of industry is the result and manifestation of the development of social productive forces. And it is the driving force of the economic downturn [9]. On the other hand, industrial development has effectively raised the level of production and promoted the development and 
improvement of productivity. With the development of social productive forces and the deepening of social division of labor, industry has emerged and developed continuously. Information is the most common element in daily life. The information industry is formed by integrating the information needed in daily life and developing it into a certain scale. The information industry is also a kind of economic development. Therefore, the rise of the information industry will also promote the economy developing. At the same time, the concept and connotation of this industry have also been enriched and developed, as shown in Figure 1 for the conceptual relationship diagram of the information industry.

Take into account the historical category of development, social division of labor, and the stages of development of social productive forces. Industry can be defined as the sum of the same or similar economic activities carried out by units or organizations formed on the basis of economic development and social division of labor. The organization (business unit) group that produces certain products as an economic unit industry must meet the following quantitative and quality requirements:

(1) The industry lies between the macro-economy and the micro-economy. As an economic group engaged in the production of similar materials or the same service, it has an independent industrial form and production mode. It is reflected in two aspects: the goals of industrial activities. Work object and industrial work structure the export form refers to the basic nature of the product or service provided [10].

(2) There are direct or indirect economic links between industries. All industries are regarded as economic systems with functional relationships.

(3) Industry is the embodiment of the division of labor of social productive forces according to the level of development of social productive forces. It is a multilevel economic system; that is, there are structural problems within the industry.

(4) Industry is an activity unit related to import and export interests.

According to the "definition" of industry, the national economy is generally divided into the following categories. Among them, the main industry refers to the industry that receives animals and plants from nature, and the purpose of work is the world's nature, that is, living. Second, industry refers to the industry that obtains nonorganic (mining) products from nature and processes products from nature. It includes miscellaneous processing machinery or material manufacturing (manufacturing) to obtain non-living-organism materials directly from natural extraction or production of various materials, or the use of materials in the construction of buildings. The secondary industry also includes biological processes, which is characterized by the rapid development of large-scale industrial production. The export forms of secondary industries are commodities. The tertiary industry does not produce specific products.

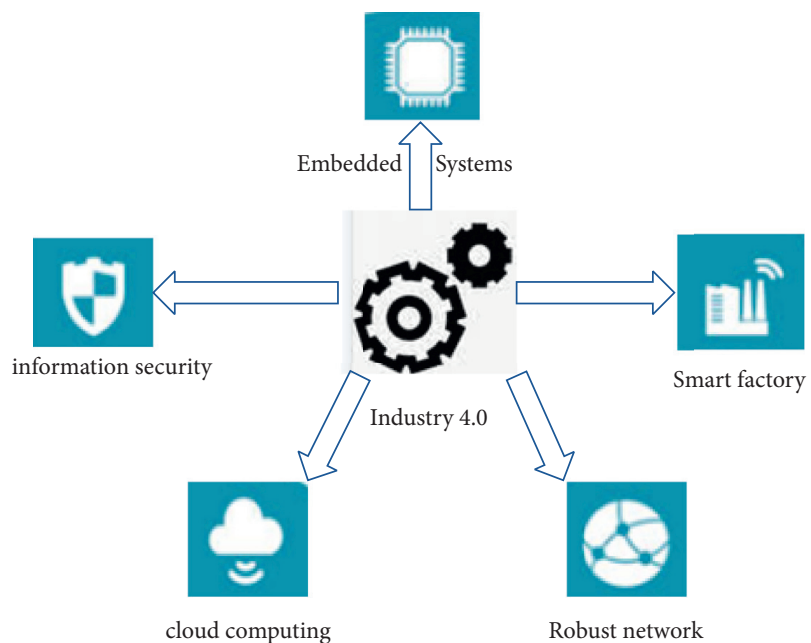

FIGURE 1: Conceptual diagram of the information industry.

Nowadays, people who treat the information industry are divided into two factions. One is to conduct a comprehensive information system analysis of the industry from the contemporary information age. Another faction is opposed to the information industry, believing that the mechanical treatment is too rigid and not suitable to interfere in the industrial economy. Information industry is to provide information, information products, and services. The "China high-tech industry development report" (1999) divides the information industry into four categories: computer industry, communication industry, audio-visual industry, and basic industry, of which the computer industry includes hardware equipment, software, system integration, and application manufacturing. And consulting services include the manufacturing of communication services and communication equipment [11]. The audio-visual industry, also known as the consumer electronics industry, includes the manufacturing of audio-visual services and audio-visual equipment. The information industry includes the manufacturing of special components and devices based on integrated circuits electronic medical devices and special electronic devices issued by the Ministry of Science and Technology are also included in the scope of information industry.

2.2. Basic Definition Principles of Information Industry. At present, most domestic and foreign scholars accept the definition method of Japanese scholars, and there is a large gap between the information technology industry and the information trading industry. First, from the definition of information technology industry, this is an industry that manufactures information technology products and provides information and working materials. Therefore, the information technology industry has the basic characteristics of production and belongs to the secondary industry category of the industrial activity target (working object) of the information product industry. This is an extraordinary form of information, and workers are "knowledge workers" with mental workers as the main content and product model. 
It is not an independent information product or service. In view of these characteristics, commodity information products belong to the category of the tertiary industry. Secondly, from the content of information technology industry defined by Japanese academia, the data of computer services, software services, and other departments also have basic characteristics. Most commodities are included in manufacturing. Obviously, the definition of information industry must break the core standards of traditional industry sectors. Find the link connecting the two industries; the loophole is very big. The basic connotation of information industry is established according to the new standards. On this basis, the structure of information industry is analyzed according to the nature of information activities [12]. Industrial structure refers to the five-dimensional spatial relationship between production factors, between industries, time, space, and levels within the industry. All factors that determine and affect economic growth will directly or indirectly affect changes in the industrial structure to varying degrees Influence. As shown in Table 1, the connotation of the two information industries is compared.

Since knowledge has spillover effects, it can be assumed that all firms are price receivers, so that the complete competition model can be used to investigate the process of economic growth. In this network, the external input is $X=$ $\left[X_{1}, X_{2}, X_{n}\right]$, the $i_{\text {-th }}$ level input of the neuron is $\mathrm{Xi}(k)$, the $j_{\text {-th }}$ level output of the regression layer neuron is $\mathrm{Xi}(k)$, and the $\mathrm{j}^{-}$th level regression. The sum of neurons is $S_{j}(k)$, and the output of the DRNN network is $O(k) . W_{\mathrm{ij}}$ and $W_{j}$ are the three weight vectors of the network input layer, regression layer, and output layer. The algorithm of the DRNN network is

$$
\begin{aligned}
O(k) & =\sum_{j} w_{j}^{o} X_{j}(k), \\
X_{j}(k) & =f\left(S_{j}(k)\right), \\
S_{j}(k) & =w_{j}^{d} X_{j}(k-1)+\sum_{i} w_{i j}^{I} I_{i}(k), \\
f(x) & =\frac{1-e^{-x}}{1+e^{-x}} .
\end{aligned}
$$

The analysis structure of the industrial economic structure is shown in Figure 2. In Figure 2, $k$ is the calculation process of the neural network, $k=1,2,3, \ldots, u(k)$ is entered from the input terminal, and then $y$ is obtained from the output terminal. (K), DRNN is the network identifier, $u(k)$ and $y(k)$ are the input of DRNN, $y_{m}(k)$ is the output answer of DRNN, the error threshold between $u(k)$ and $y(k)$ is the input of DRNN feedback adjustment data [13].

The approximation error is

$$
\begin{aligned}
& e(k)=y(k)-y_{m}(k), \\
& E(k)=\frac{1}{2} e^{2}(k) .
\end{aligned}
$$

Here, the input contribution is defined as the product of the input growth rate and its two-period average value share.
$\mathrm{Ax}=\mathrm{X}-\mathrm{xt}-1$ represents the change from $\mathrm{t}-1$ to $t$, and $v$ is equal to the average share of input in the two periods of output. Define the share of each input value as

$$
\begin{aligned}
\alpha & =M^{+} T, \\
\operatorname{minLPELM} & =\frac{1}{2}\left\|\alpha^{2}\right\|+C \frac{1}{2} \sum_{i=1}^{n}\left\|\gamma_{i}^{2}\right\|, \\
h\left(x_{i}\right) \alpha & =t_{i}^{T}-\gamma_{i}^{T}, i=1, \ldots n, \\
\alpha & =H^{T}\left(\frac{I}{C}+H H^{T}\right)^{-1} T .
\end{aligned}
$$

This formula was expanded. They divided diversification into inter-industry diversification and intra-industry diversification and used EUD to express the degree of interindustry diversification:

$$
\begin{aligned}
& w=1, F(F \in[0,1]), \\
& F \in(0.5,1), \\
& F=1-\gamma e-\left|\frac{C}{\text { Ctotal }}\right| \gamma \in R+, \\
& F=\gamma e-\left|\frac{1-\mathrm{C}}{\text { Ctotal }}\right|, \gamma \in R+.
\end{aligned}
$$

$w$ represents the type of industry, C represents the initial value of the industry, and F represents the total profit. As there is currently no statistical data on the location of fixed assets at the service industry level, our method is to first calculate the total capital stock of the tertiary industry for each year using the perpetual inventory method and then use the fixed asset investment of each industry to occupy the third place [14]. The proportion of industrial fixed asset investment estimates the industrial fixed capital stock, which is

$$
\begin{aligned}
\Delta w_{i j}^{I}(k) & =\frac{--\partial E(k)}{\partial w_{i j}^{I}}=e(k) \frac{\partial y_{m}}{\partial X_{j}} \frac{\partial X_{j}}{\partial w_{i j}^{I}}, \\
e(k) \frac{\partial y_{m}}{\partial X_{j}} \frac{\partial X_{j}}{\partial w_{i j}^{I}} & =e(k) w_{j}^{O} Q_{j}(k), \\
w_{i j}^{I}(k) & =w_{i j}^{I}(k-1)+\mu \Delta w_{i j}^{I}(k) .
\end{aligned}
$$

Regarding the selection of the specific production function, Jorgensen decomposed output growth into the contribution of each input and the remaining total factor productivity according to the standard growth calculation formula:

$$
\begin{aligned}
& E\left[T_{i}\right]=P_{m}^{i} * P_{r} W_{i-1}, \\
& E\left[T_{i}\right]=\sum_{i=0}^{M C} E\left[T_{i}\right],
\end{aligned}
$$

$$
\operatorname{MaxE}=\operatorname{fix}\left(\log _{2}(N)\right) K=\operatorname{fix}\left(\log _{2}\left(\frac{N}{2}\right)\right) .
$$


TABLE 1: Comparison of the connotation of the two categories of information industry.

\begin{tabular}{lcccc}
\hline Industry category & Industrial form & Object of labor & Labor structure & Industry characteristics \\
\hline $\begin{array}{l}\text { Information technology } \\
\text { industry }\end{array}$ & Manufacturing, technical & Technology and & R\&D and & Hardware equipment \\
Information commercialization & services & products & manufacturing & products \\
industry & Service R\&D & $\begin{array}{c}\text { Information and } \\
\text { knowledge }\end{array}$ & $\begin{array}{c}\text { Mainly intellectual } \\
\text { workers }\end{array}$ & $\begin{array}{c}\text { Services and information } \\
\text { products }\end{array}$ \\
\hline
\end{tabular}

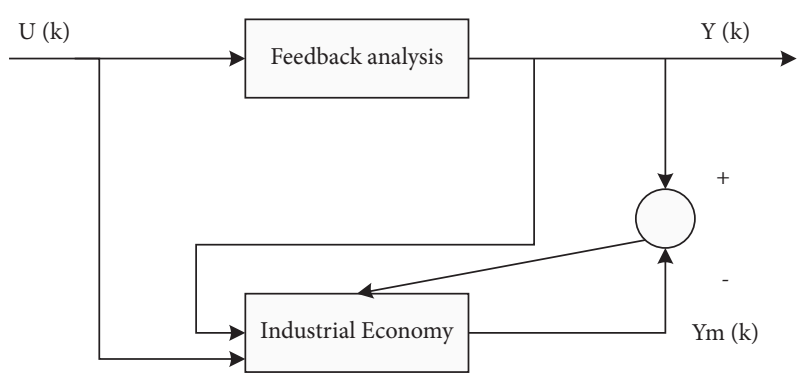

FIGURE 2: Diagonal recurrent neural network identification structure diagram.

2.3. Theoretical Basis for Information to Promote the Development of Industrial Economy. Since the 1940s, information technology has been widely used and consumed all over the world. Computers have a profound impact on people nowadays. There have been great changes in both computing and lifestyle. Of course, the world economy is also following the information. The times have changed in response, which also makes the traditional industry develop towards the current industrial economy $[15,16]$. The impact of the information age on the industrial economy has the following two aspects.

2.3.1. The Direct Impact of the Information Industry on Economic Growth. The information industry itself is a basic industry. The leading industry is the main industry of the national economy, as well as the high-tech industry and modern service industry. The continuous development and growth of its people means the expansion of the country. The economy that stimulates the increase in domestic demand has increased the employment scale of the whole society, promoted the growth of exports, foreign trade, taxation, etc., and directly promoted economic growth [17].

2.3.2. The Indirect Impact of the Information Industry on Economic Growth. This role is reflected in the close relationship between the information industry and other industries. First, there are links between the information industry and other industries. The development of the information industry depends on the demand for information industry products from other industries, and other industries drive the development of other industries; secondly, the information industry has historical connections with other industries. The development of the information industry also relies on the terminal products of other industries. The greater the demand for the terminal products of other industries, the more effectively the information industry can promote the development of other industries. Promote the growth of the national economy through interaction with other industries. The relationship between them is shown in Figure 3.

Based on the above analysis, this article strives to comprehensively and objectively define the definition of economic growth quality in order to conduct more targeted analysis and research. The quality of economic growth is defined as follows: the quality of economic growth is one of the important aspects of economic growth. Compared with the quantity of economic growth, the quality of economic growth is the introduction of time factors, labor and capital and other input factors, structural factors, and purpose factors. On the basis of factors, it mainly refers to the quality of the economic system, including the efficiency of economic growth, the industrial structure of economic growth, the employment structure, and the ecological environmental cost of resource utilization [18].

\section{Mobile Information System Model of the Industrial Economic Chain}

3.1. Co-Integration Analysis of Information Industry and Economic Growth. Most time series are non-stationary, because time series usually exhibit linear or exponential time trends. When one time series is used to regress another time series, although there is no significant relationship between the two, the $R$ value is usually very high, simply because the two time variables show strong trends, not because of the true relationship between the two. This regression is an artificial regression. Depending on the nature of this time series, it is dangerous to use the standard least squares method (for constant time series) and analyze the relationship between unstable time series.

Just as a non-variable time series can have a non-zero mean, custom or stochastic trend convergence equations can also combine intersection points and given trends. The analysis framework of Johansen's maximum likelihood method includes the following five possible situations: (1) $y$ order has no definite trend, and the fusion equation has no intersection; (2) $y$-order has no given trend, and the integral equation has an intersection; (3) $y$ has a linear trend, but the integral equation has only the elimination term; (4) The yorder integral equation shows a linear trend; (5) the following y second-order integral equation also shows a linear trend. For $r$ orders, in the above 5 cases, the inspection stringency has been reduced $[19,20]$.

Only when all variable sequences are a single integer sequence, can aggregate analysis be performed, and all sequences are the same. When obtaining sample data from a 


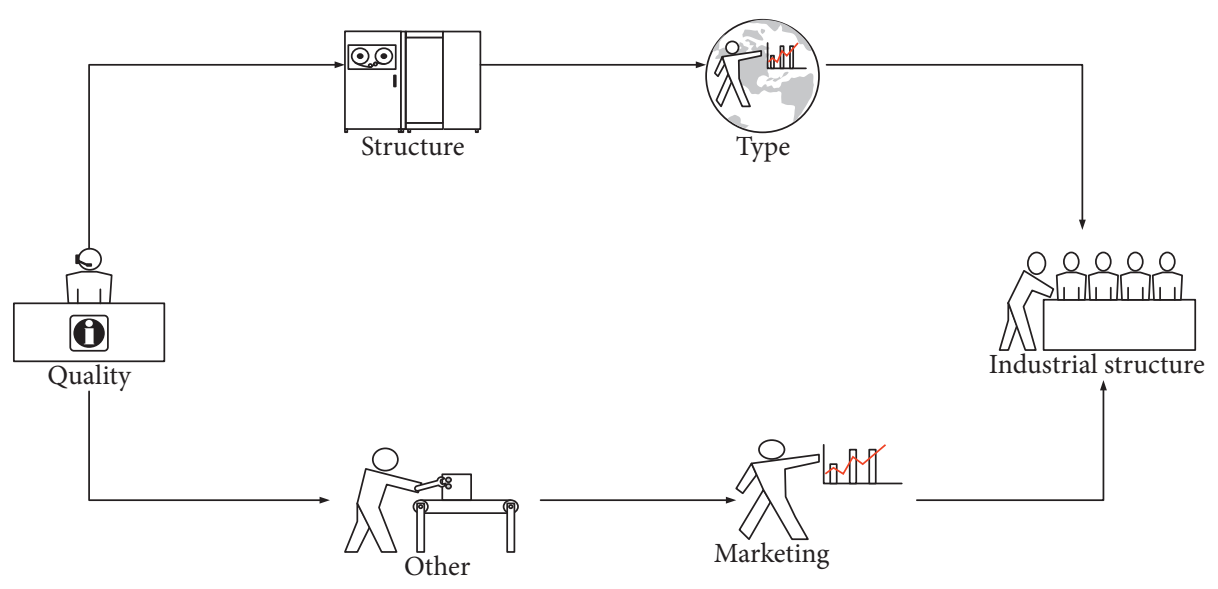

FIGURE 3: Relationship between other industries and the quality growth of the national economy.

random time series, the stability of these data must first be judged. First, perform a unit root test for each variable to determine whether the time series is stable. To avoid severe data fluctuations, use the natural logarithm of LI and GDP, which are represented by LI and LGDP, respectively. Draw LGDP and LI into time series diagrams as shown in Figure 4 . It can be seen that each variable has a growing trend [21].

Use Eviews software to use unit root test to determine the stationarity of time series LGDP and LI, and specifically use ADF (Augmented Dickey-Fuller Test) method. Since it can be seen from the figure that LGDP and LI both have an obvious rising trend, these data include constant items and non-constant items. The test results of these survey data are shown in Table 2.

When creating a regression model, we treat some variables as internal variables. Other variables are treated as external or predefined variables. When estimating these models, it is also necessary to ensure that the equations of the equations are identifiable. The goal of achieving recognition usually assumes that certain predefined variables only appear in certain equations. Sims believes that this type of decision is usually subjective. If a set of variables is indeed consistent and no one is sure that the variable is an external variable, these variables should be treated equally, rather than prioritizing exogenous and exogenous variables [22].

3.2. VAR Model Establishment. The VAR model is often used in the calculation of time sequence and there are many variables and regular search modes, and the variables it analyzes are often compared with internal functions. The mathematical expression of a typical VAR model is $\mathrm{DA}=\mathrm{N} 1 \mathrm{Mt}-1++\ldots+\mathrm{NpMt}-\mathrm{p}+\mathrm{N} 1 \mathrm{Mt}+\ldots+\mathrm{NtM} 1-t$, where $M$ is the $\mathrm{t}$-dimensional vector variable, and $\mathrm{N}$ is the $p$ outer vector variable $\mathrm{A} 1 \cdots \mathrm{Ap}$ and $\mathrm{B} 1 \cdots \mathrm{Br}$ is the parameter matrix to be approximated. The internal variable and the external variable have the delay interval of sequence $p$ and $r$, respectively, which is the condition of random disturbance.

In VAR modeling, it is usually expected that the offset interval is large enough to fully reflect the dynamic characteristics of the model being created. But the longer the delay, the closer the parameters in the model are, so the degrees of freedom should be delayed. To seek a balance between degrees of freedom and degrees of freedom, Akaike's data criterion (AIC) and Schwarz criterion (Schwarz Criteria, SC) are generally used to determine the order of delay. The specific method is that when AIC and SC are the smallest, the same sorting is used, when AIC is the smallest, and when the smallest SC appears in different shift intervals, an LR test needs to be exchanged. It can be seen from Table 3 that the AIC criterion and the SC criterion unanimously recommend that the optimal lag order is 2 .

After the lag order is established as 2, the market conditions of economic systems A and B of the VAR model are shown in Figure 5.

The results of the above-mentioned integration test prove that there is a long-term stable equilibrium relationship between the data industry and economic growth. Based on the VAR model, we conducted a Granger causality test on the long-term equilibrium relationship between data. When industry and economic growth are in equilibrium, the development of the information industry will obviously stimulate economic growth, and economic growth will promote the development of the information industry. It is not obvious. But is there such a short-term causality? The VEC model reflects not only the long-term correlation, but also the short-term equilibrium relationship. Based on this model, the Wald stress test VEC is carried out to better analyze the short-term and long-term reasons of GDP and the information industry. This method is particularly suitable for situations where it is difficult to estimate the constraint model. Wald test was proposed by Wald (Wald, 1943), and it is suitable for testing linear and nonlinear stress. The principle is to measure the distance between estimators, namely, infinite and finite estimators [23].

Basic assumption: jobs are different in the industry. It is difficult to switch between these two types of short-term markets due to technical reasons and education level and other market reasons. Beveridge analyzed the theory of structural unemployment and believed that there was 

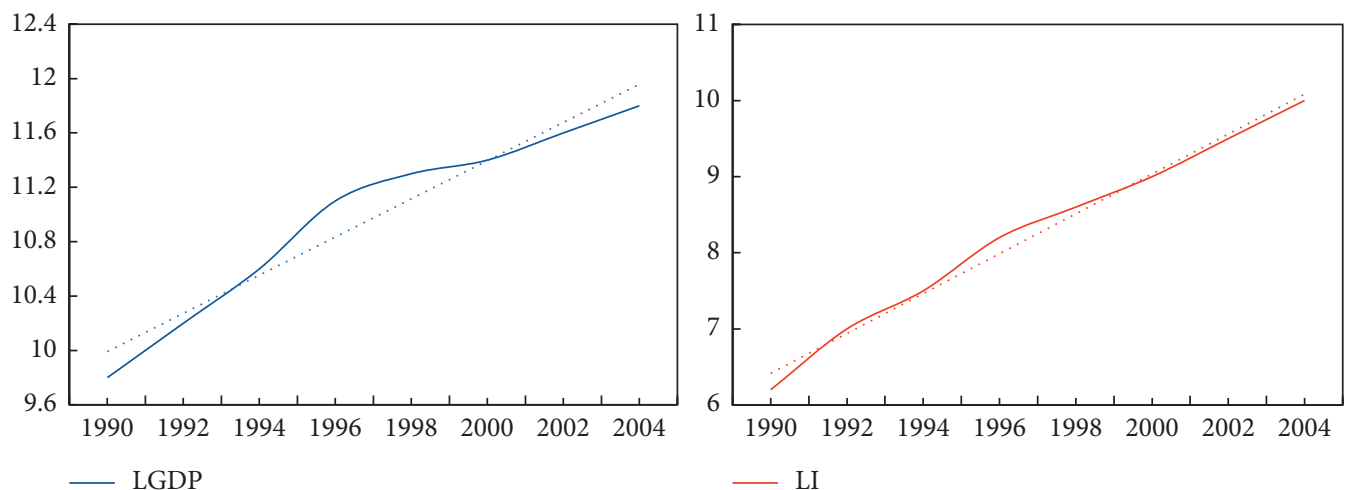

Figure 4: Changes in LGDP and LI.

TABLE 2: Unit root test results.

\begin{tabular}{lccc}
\hline Variable & ADF inspection & Lag length & Single integer order \\
\hline LGDP & -4.589753 & 4 & 0 \\
LI & -3.895472 & 2 & 0 \\
\hline
\end{tabular}

TABLE 3: Statistics of VAR lag period selection.

\begin{tabular}{lcc}
\hline Lag order & AIC & SC \\
\hline 1 & -4.584695 & -4.566895 \\
2 & -6.541253 & -6.154872 \\
3 & -5.201364 & -5.901015 \\
\hline
\end{tabular}

SB

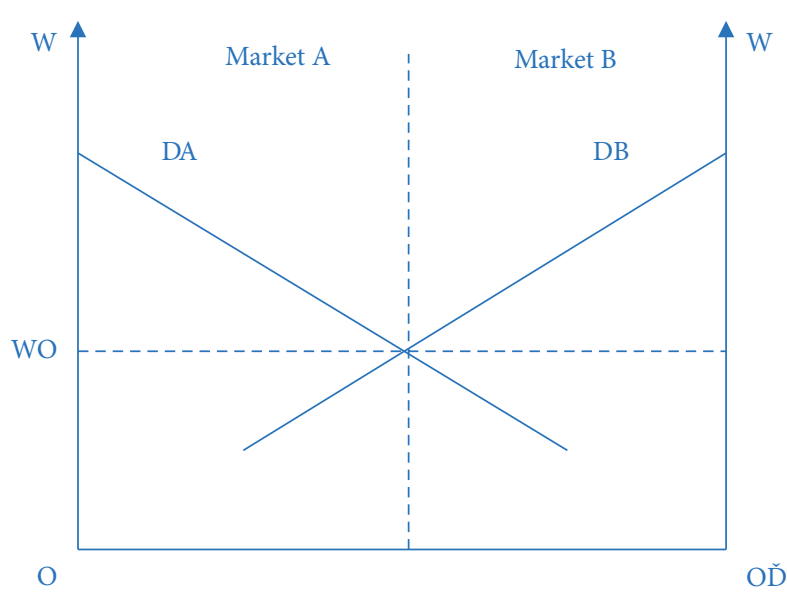

FIgUre 5: A and B equilibrium states of the two labor markets.

unemployment in the labor market. The unemployed are affected by factors such as education and skills, making it difficult to enter the vacant labor market; but in the case of a high unemployment rate, there is a connection between the two labor markets. Few people will voluntarily leave in order to find a more satisfying job, and the vacancy rate will drop. In the same way, if there are many job vacancies, the unemployed will have more opportunities to find a job [24]. And new job opportunities will increase. Therefore, the unemployment rate will fall. Therefore, there is a significant negative correlation between unemployment and job vacancies. The relationship between the two is shown in the Beveridge curve in Figure 6.

3.3. Model Analysis. According to the theory of unbalanced economic growth, economic growth is closely related to changes in industrial structure. The process of industrial structure change is the process of economic development. The improvement of the level of economic development depends to a large extent on the evolution of the industrial structure. Information technology is the basis for advancing the industrial structure, and a large part of it is obtained through the development of information technology and the promotion of the information technology industry- informatization. Accelerate the development of the information industry through the introduction of information technology to promote the transformation of industrial structure, and create favorable conditions for the growth of the new economy from a fixed perspective. Structural industries are part of the industry [25]. From a dynamic perspective, the industrial structure refers to the proportional relationship between different sectors. At the same time, the industrialization of the national economy and the dynamic changes and regular changes among various sectors are caused by the income gap between different industries and the labor flow between industries. The general rule is the transformation of the primary industry to the secondary industry. The secondary industry becomes the tertiary industry (Figure 7).

From the network level distribution graph in Figure 7, it can be concluded that the distribution graphs of the two are similar, and both belong to the rules of decentralization. The graph shows that most nodes in the network have a small number of connections, and few nodes have many connections. This proves that the industrial chain network of Gujiao Circular Economy Park and Tashan Circular Economy Park is a stepless network. In summary, due to the uneven development level of my country's big data industry, the economic activities of the big data industry have varying degrees of impact in different regions [26]. The national scale, financing activities, and investment activities have a positive impact on the regional economy. In terms of regions, the quantitative scale and financing activities in the 


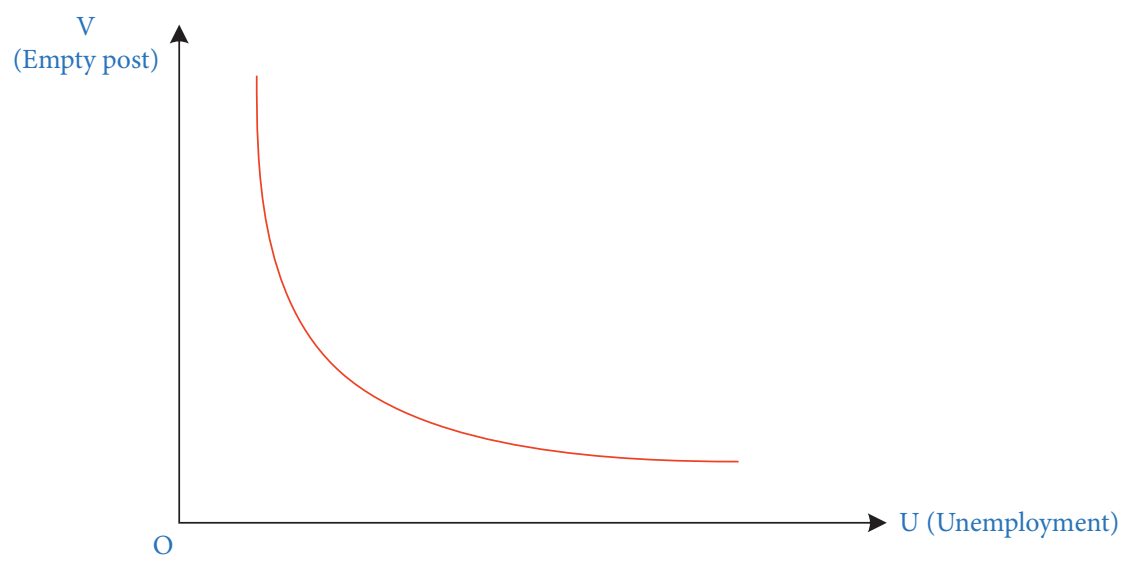

FiguRe 6: Beveridge curve.
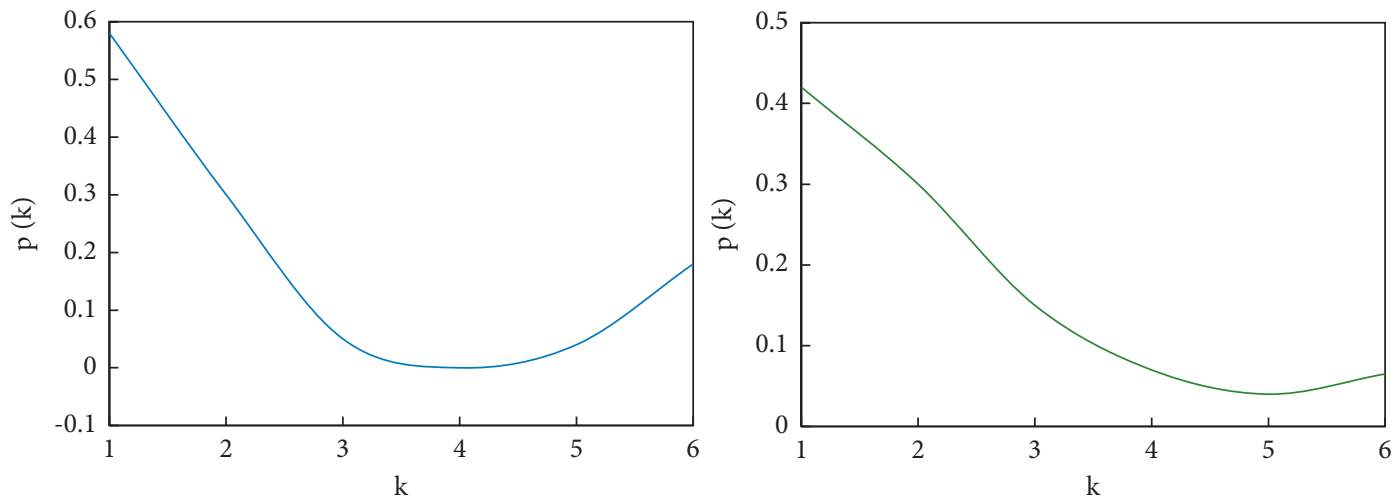

FIGURE 7: Network degree distribution map of the industry chain.

east, the financing activities in the west, and the quantitative scale in the central region have promoted the development of the regional economy.

\section{Model Results and Analysis}

4.1. Impulse Response Function Analysis. The impulse response function (IRF) is used to measure the impact of a standard deviation from a random disturbance term on the current and future values of endogenous variables. When using a time series model to analyze the influence relationship, it often does not directly analyze how the change of one variable affects another variable. Instead, it adopts another way of thinking, that is, consider how the influence of the disturbance item is propagated to each variable, or said that the model is affected by the dynamic impact of the disturbance term on the current and future values of the system. Table 4 shows the comparison of factor contributions calculated after the sum of output and factor inputs for the three types of industries. It is not difficult to see that, compared with other factors, intermediate input contributes the most to the growth of the three types of industries. The contribution of intermediate input to the information technology production group was $15.1 \%$, and the contribution to the information technology use and non-use group was $9.4 \%$ and $10.5 \%$, respectively. It should be noted that the contribution of information technology intermediate input to the information technology production and use group is greater than that of the non-information technology use group. For the information technology production industry, technological progress plays an important role in the growth of the information technology production group. TFP growth has become the second largest contributor to output growth, reaching $8.2 \%$ numerically. The contribution of fixed capital and labor in this group is relatively small, at $1.2 \%$ and $0.55 \%$, respectively.

For the information technology use and non-information technology use groups, fixed capital is the second largest factor in growth. Nevertheless, technological factors have given a certain driving force to the growth of the information technology industry. The degree of dependence of the information technology use group on fixed capital is lower than that of the non-information technology use group (10.4\% for the former and $13.4 \%$ for the latter), and this degree of dependence is partly transferred to the growth of TFP. The contribution of labor to the information technology use group is higher than that of other industries, because the service industries included in this group are labor-intensive. The economic growth of non-information technology use sectors mainly depends on the investment of fixed capital, showing typical investment growth characteristics. 
TABLE 4: Comparison of the contribution of three industries' factor input from 2002 to 2010.

\begin{tabular}{|c|c|c|c|c|c|}
\hline Industry category & Output growth & Fixed capital & Labor & Intermediate input & TFP growth \\
\hline Information technology production & 25.03 & 1.24 & 0.55 & 15.09 & 8.15 \\
\hline Information technology use & 16.24 & 10.35 & 0.92 & 9.39 & -4.42 \\
\hline Noninformation technology use & 15.46 & 13.38 & 0.70 & 10.52 & -9.13 \\
\hline
\end{tabular}
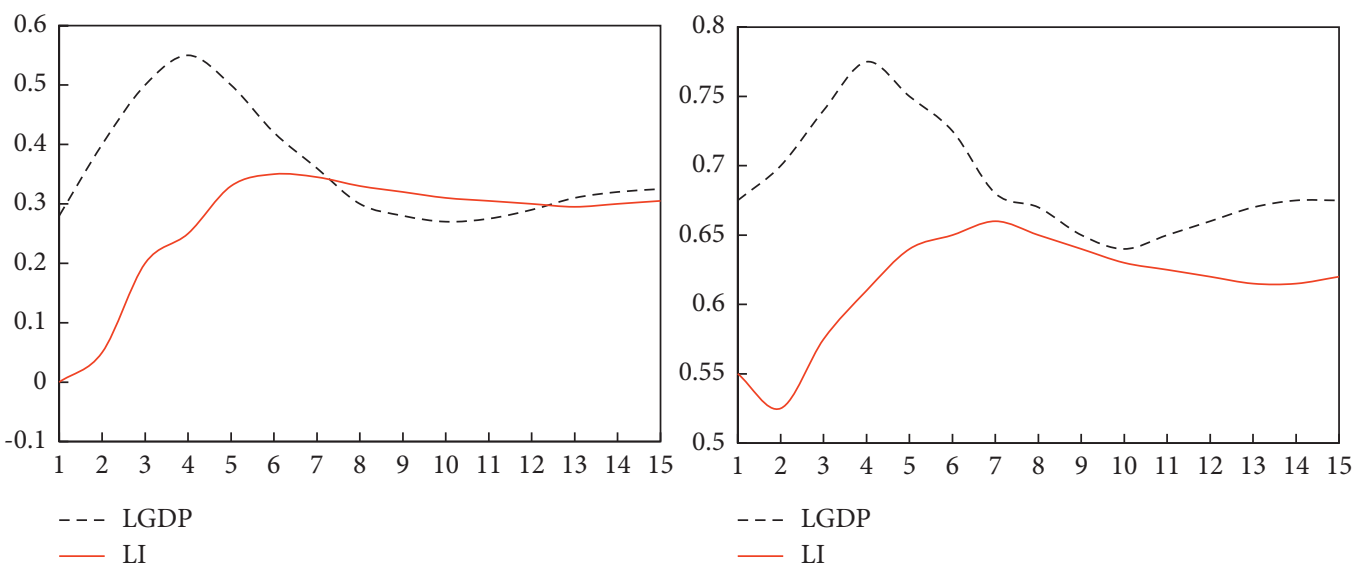

FIGURE 8: Impulse response function curve.

Based on the above VEC model, the impulse response function curve shown in Figure 8 is obtained. In the figure, the horizontal axis represents the lag period, and 15 is selected here, and the vertical axis represents the response degree of each endogenous variable to the impact of unit innovation (Innovation) of other variables. The curve represents the impulse response function curve in which one variable is impacted by the change of other variables by an orthogonalized standard deviation. It can be seen from Figure 8 that LGDP immediately has a strong response to its own standard deviation and new interest. Output increased by about 0.28 . It will be greatly affected by itself in the short term, but it will decline from the fourth period. After the 9th period, it began to stabilize; in the short term, the impact of GDP on the information industry has a significant upward trend, and the impact after the 7th period has stabilized, indicating that the development of the information industry has a role in promoting economic growth in the short and long term. Both are more obvious, and the short-term effect is even more significant; in the short term, the information industry began to decline due to its own impact, but soon began to rise in the second period, and began to stabilize after the seventh period; the growth of GDP will have a short-term impact on the information industry. It has a pulling effect, but after the 4th period, the impact began to decline and stabilized after the 9th period. This shows that the growth of GDP has a significant role in promoting the development of the information industry in the short term, but it is not significant in the long term.

4.2. Data Analysis. The research data in this article is extracted from the official website of the national data and data published by relevant companies, which can ensure the authenticity of the data. In terms of the total output growth rate of the 10 industries, there are huge differences among industries. The average growth rate of total output ranges from $31.8 \%$ in the manufacturing of communications equipment, computers, and other electrical equipment to oil and natural gas extraction, $3.3 \%$ of the industry. The median growth rate of output is $17.5 \%$. Figure 9 shows the ranking of the growth rates of these industries.

The fastest growth in output is the "communication equipment, computer, and other electronic equipment manufacturing" of the information technology production group. In contrast, the "information transmission, computer services, and software industry" of this group has a slower growth rate of $16.6 \%$, slightly lower than the median growth rate of all industries. This shows that the development of manufacturing and service industries in the information technology production industry is not balanced, and the information technology manufacturing industry is far ahead of the information technology service industry. The output of the manufacturing industry in the information technology use group has also grown very fast. Among them, "transportation equipment manufacturing industry" ranks third in all industries, accounting for 29.4\%, while "electrical machinery and equipment manufacturing," "instrument and cultural office machinery manufacturing," and "general and special equipment manufacturing" were $28.0 \%, 24.3 \%$, and $23.1 \%$, respectively, ranking sixth, seventh, and eighth. It is worth noting that the service industry in this group has shown a low growth rate. The growth rates of "financial industry," "other service industry," and "wholesale and retail industry" were $15.1 \%, 9.5 \%$, and $8.8 \%$, respectively, which were all lower than the industry median, ranking 21st, 28th, and 29th.

It can be seen from Figure 10 that the $\mathrm{H}$ index is showing a downward trend, that is to say, the degree of technological integration of the three major information industries is continuously improving, but the overall profit rate is in a 


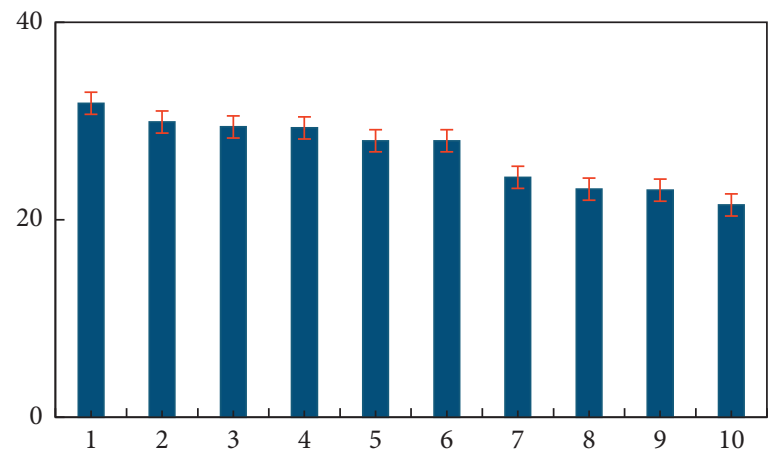

FIGURE 9: Ranking of industry growth rates.
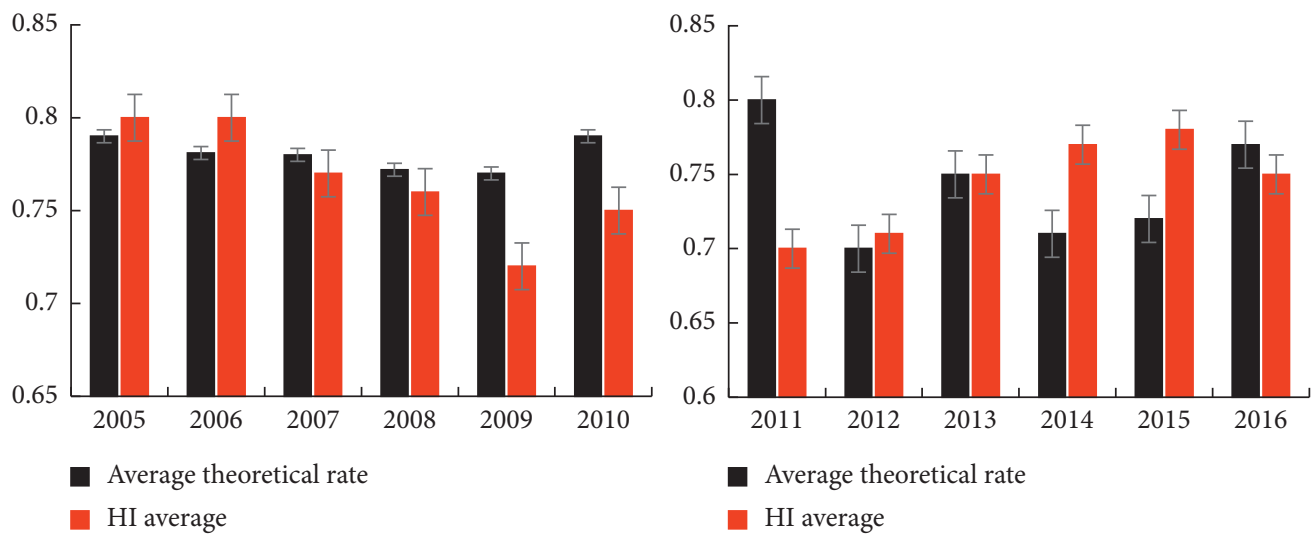

Figure 10: Industrial economic development trend in the past 10 years.

downward trend. In other words, the two are in a negative correlation. The reasons for this phenomenon may include the following: (1) The existence of learning costs. When an enterprise enters a new field, it will encounter a lack of core competence and knowledge, which will lead to the problem of learning costs. That is to say, in the early stage of the enterprise entering a new field, there will be higher learning costs, resulting in a decline in corporate profit margins; as the core competence is cultivated and strengthened, the learning cost of the enterprise will become lower and lower, and the profit margin will increase accordingly. (2) The competition among industries is fierce. The integration of the three major information industries has brought a lot of room for development. At the same time, it has also formed a fierce competition between each other. For enterprises, it will temporarily reduce operating performance. (3) The transfer of technological innovation to product innovation is slow. Due to the slow development of product integration in my country, technological innovation results cannot be converted into commodities, which leads to a large investment in technology and low returns, leading to a decline in the operating profit rate of enterprises, with a rate of decline of about $5 \%$.

\section{Conclusion}

This paper constructs an analytical framework model for the quality of economic growth and makes basic assumptions and analyses on each dimension. It uses impulse response functions to integrate and analyze data and also constructs a VAR model to analyze the prospects of the industrial economy. The purpose is to provide a foothold and starting point for the study of subsequent chapters. However, the concept of the quality of economic growth should also include environmental factors, sustainable development factors, and many other aspects. Due to the limited length of the article, the discussion in this article is not comprehensive enough, and some of the assumptions in this article do not have solid theoretical support. A reasonable theoretical explanation has come out, and the rigor and scientific nature of its argumentation still needs further experimentation and discussion. Although the research in this article has reached the expected research goals to a certain extent, due to the limitations of energy, knowledge, and research environment conditions, only the qualitative and quantitative aspects of the information industry and the quality of economic growth have been tentatively discussed, and the proposed methods and the point of view are still immature. There are still many areas to be improved in the research on the relationship between the information industry and the quality of economic growth, and the research results are imperfect. In the analysis of time series variables, due to the lack of statistical indicators, statistical data, and changes in statistical caliber, therefore, it has a certain impact on the accuracy of the empirical results of this article, and it has not reached my expected goal. 


\section{Data Availability}

No data were used to support this study.

\section{Conflicts of Interest}

The author declares that there are no conflicts of interest regarding the publication of this article.

\section{References}

[1] A. V. Myaskov and G. F. Alekseev, "Strategizing of transformations in the coal mining industry of Kuzbass," Russian Journal of Industrial Economics, vol. 13, no. 3, pp. 318-327, 2020.

[2] S. Ferguson and M. Sanctuary, "Why is carbon leakage for energy-intensive industry hard to find?" Environmental Economics and Policy Studies, vol. 21, no. 1, pp. 1-24, 2019.

[3] J.-H. Kim, "An analysis of the relationship among industrial loan concentration, excess loan, and bank's credit risk," Journal of Industrial Economics and Business, vol. 31, no. 3, pp. 997-1029, 2018.

[4] S. Kim and I. Song, "The effects of the SNS characteristics on relationship quality and negotiation performance in the industrial goods market," Journal of Industrial Economics and Business, vol. 30, no. 1, pp. 35-55, 2017.

[5] P. Ferreira, "Welfare changes in the cournot setting with an empirical application to the telecommunications industry," The Journal of Industrial Economics, vol. 65, no. 1, pp. 194213, 2017.

[6] H. Bongchan, "Transferring labor to high-productivity service industry and economic growth," Journal of Industrial Economics and Business, vol. 29, no. 1, pp. 151-167, 2016.

[7] L. Eungsoon and S Young, "A study on future promising industry in chungnam - using AHP method -," Journal of Industrial Economics and Business, vol. 29, no. 5, pp. 16291650, 2016.

[8] C. W. Chen and S. Shieh, "Does exclusive dealing matter? Evidence from distribution contract changes IN the US beer industry," The Journal of Industrial Economics, vol. 64, no. 3, pp. 411-435, 2016.

[9] L. Aguzzoni, E. Argentesi, L. Ciari, T. Duso, and M. Tognoni, "Ex postMerger evaluation in the U.K. Retail market for books," The Journal of Industrial Economics, vol. 64, no. 1, pp. 170-200, 2016.

[10] G. Hugh, S. Anthony, and S. Peter, "Competition, prices and quality in the market for physician consultations," The Journal of Industrial Economics, vol. 64, no. 1, pp. 135-169, 2016.

[11] S. Lach and J. L. Moraga-González, "Asymmetric price effects of competition," The Journal of Industrial Economics, vol. 65, no. 4, pp. 767-803, 2017.

[12] D. P. Byrne and N. de Roos, "Consumer search in retail gasoline markets," The Journal of Industrial Economics, vol. 65 , no. 1, pp. 183-193, 2017.

[13] L. Cabral and G. Natividad, "Box-office demand: the importance of being \#1," The Journal of Industrial Economics, vol. 64, no. 2, pp. 277-294, 2016.

[14] N. H. Miller, M. Remer, C. Ryan, and G. Sheu, "Pass-through and the prediction of merger price effects," The Journal of Industrial Economics, vol. 64, no. 4, pp. 683-709, 2017.

[15] M. Janssen and M. Teteryatnikova, "Horizontal product differentiation: disclosure and competition," The Journal of Industrial Economics, vol. 64, no. 4, pp. 178-184, 2016.
[16] G. Molnar and S. J. Savage, "Market structure and broadband Internet quality," The Journal of Industrial Economics, vol. 65, no. 1, pp. 73-104, 2017.

[17] J. Shen, H. Yang, and L. Ye, "Competitive nonlinear pricing and contract variety," The Journal of Industrial Economics, vol. 64, no. 1, pp. 64-108, 2016.

[18] W. M. W. Lam, "Switching costs in two-sided markets"," The Journal of Industrial Economics, vol. 65, no. 1, pp. 136-182, 2017.

[19] M.-L. Allain, C. Chambolle, S. Turolla, and S. B. Villas-Boas, "Retail mergers and food prices: evidence from France," The Journal of Industrial Economics, vol. 65, no. 3, pp. 469-509, 2017.

[20] J.-H. Hahn and S.-H. Kim, "Interfirm bundled discounts as a collusive device," The Journal of Industrial Economics, vol. 64, no. 2, pp. 255-276, 2016.

[21] D. Quint, "Common values and low reserve prices," The Journal of Industrial Economics, vol. 65, no. 2, pp. 363-396, 2017.

[22] M. V. Rybin and D. S. Lobov, "Theoretical and practical aspects of assessment of innovative activity in oil and gas enterprises," Russian Journal of Industrial Economics, vol. 13, no. 4, pp. 531-540, 2020.

[23] Y. F. Fong, X. Hu, T. Liu, and X. Meng, "Using customer service to build clients' trust*," The Journal of Industrial Economics, vol. 68, no. 1, pp. 136-155, 2020.

[24] B. O. Johansen and T. Nilssen, "The economics of retailing formats: competition versus bargaining," The Journal of Industrial Economics, vol. 64, no. 1, pp. 109-134, 2016.

[25] M. Bas and C. Paunov, "The unequal effect of India's industrial liberalization on firms' decision to innovate: do business conditions matter?" The Journal of Industrial Economics, vol. 66, no. 1, pp. 205-238, 2018.

[26] D. Raval and T. Rosenbaum, "Why is distance important for hospital choice? Separating home bias from transport costs"," The Journal of Industrial Economics, vol. 69, no. 2, pp. 338368, 2021. 